\title{
REFLEXÕES SOBRE AS RELAÇÕES DAS POPULAÇÕES RURAIS COM OS MEIOS MASSIVOS: estudo de caso da chegada da eletricidade na comunidade de Pau D'arco, Piauí
}

\section{REFLECTIONS ON THE RELATIONS OF THE RURAL POPULATIONS WITH THE MASS MEDIA: a case study on the arrival of electricity in the community of Pau D'arco, Piauí}

\section{Ricardo Duarte Gomes DA SILVA ${ }^{1}$; Lívia Moreira BARROSO²}

Resumo: O evento da chegada da luz na comunidade rural piauiense de Pau D'arco possui configurações socioculturais e simbólicas semelhantes e diferentes daquilo já registrado por outras pesquisas em comunicação em décadas anteriores. Trata-se, em pleno século XXI, de observarmos processos de oralidade na comunidade sendo atravessados por processos de massificação e midiatização. $O$ presente trabalho, que toma como referência tese de doutoramento em andamento, procura refletir sobre os primeiros achados de uma pesquisa exploratória sobre a chegada da luz na comunidade rural no Piauí e as novas relações comunicativas estabelecidas entre seus moradores. Além das mudanças de comportamento dos habitantes da comunidade em função da televisão, identificamos a tática do download como novidade entre a juventude da localidade.

Palavras-chave: Midiatização; Rural Contemporâneo; Comunicação Rural.

Abstract: The occurrence of the arrival of electric light in the Pau D'arco Rural Community in the Brazilian state of Piauí has socio-cultural and symbolic configurations similar and different from what was already recorded by other communication researches in the past decades. In the XXI century, it is a question of observing processes of orality in the community, being crossed by processes of massification and mediatization. The present work, based on a doctoral thesis, seeks to reflect on the first data of an exploratory research about the arrival of electric light in a rural community at Piauí and the new communicative relations established among its residents. In addition to the behavioral changes of the inhabitants of the community with the entrance of the television, we identified the tactical download as novelty among the rural youth of the locality.

Keywords: Mediatization; Contemporary Rural; Rural Communication.

\footnotetext{
1 Professor do Departamento de Comunicação Social da Universidade Federal de Viçosa. Doutor em Comunicação Social (UFMG). Coordenador do Grupo de Pesquisa Interações Midiáticas, Textualidades e Processos Comunicacionais. E-mail: ricardoduarte.ufv@gmail.com.

2 Doutoranda do Programa de Pós-Graduação em Comunicação Social da Universidade Federal de Minas Gerai. Membro do Grupo de Pesquisa em Imagem e Sociabilidade - Gris. Bolsista Capes. E-mail: liviabarroso89@gmail.com.
} 
Introdução

Os espaços rurais são também espaços para a comunicação, assim como Reguillo-Cruz (2007) considera as cidades como espaços privilegiados para a comunicação. $\mathrm{O}$ autor reivindica o estudo das cidades na Comunicação por ser a cidade um espaço de organização da diversidade, embates, negociações entre diferentes grupos sociais. O que falar do meio rural contemporâneo? Chamamos a atenção para os rurais de hoje dentro dos estudos da Comunicação, espaços definidos cada vez mais por outras configurações culturais e simbólicas, a partir de cada diversidade rural espalhada pelas regiões brasileiras: conflitos históricos e outros recentes relacionados às negociações permanentes entre o tradicional e o moderno.

Neste sentido, os diferentes espaços rurais, com suas designações naturais específicas, sempre estiveram atravessados pela presença e influência dos meios massivos (em especial, o rádio e a televisão) e mais recentemente pelos meios online (internet e redes sociais). $\mathrm{Na}$ raiz desta presença e influência está aquilo que explicou Silva e Soares (2012) sobre o último decênio no Brasil: alguns programas governamentais (eletrificação rural, melhoria nas casas rurais e de financiamentos para a compra de equipamentos eletrônicos) colaboraram com a intensificação da presença e interferência das mídias eletrônicas nos espaços rurais. Como consequência, os conteúdos midiáticos e suas representações também intensificaram seus estímulos e mudaram costumes e comportamentos dos habitantes do rural, reorganizando cotidianos, maneiras de perceber a si e ao mundo além de suas fronteiras. Em cada espaço rural, com suas peculiaridades e conflitos, existem afetações e negociações entre as representações midiáticas que servem como referência para as pessoas e as tradições nos espaços de sociabilidade no rural que transita pela circunvizinhança, locais de trabalho, escola, espaços de lazer e religiosos.

Atendo a isto, Silva (2014) trabalhou com uma juventude rural mineira e as representações midiáticas mais admiradas entre eles. Identificou os gêneros das telenovelas, os telejornais populares e os programas esportivos (de diferentes canais) como sendo os de maior popularidade entre os jovens. $\mathrm{O}$ autor estudou figuras públicas populares que circulavam as mídias eletrônicas preferenciais (televisão e redes sociais) 
para os espaços de sociabilidade dos jovens no rural mineiro. E ainda identificou a preferência da juventude rural pelos conteúdos midiáticos não-rurais (aqueles não estritamente vinculados ao agrícola e agropecuário). Ao final, Silva (2014) sinalizou para a presença e influência das mídias e seus conteúdos mais populares como capazes de modificarem ou estimularem a maneira como os jovens no rural percebem a si, os traços culturais e referências sociais de suas tradições locais.

Assim, neste conjunto complexo de relações que define cada espaço rural, o evento da chegada da luz elétrica em determinadas localidades rurais brasileiras tem especial destaque neste artigo: seja pelo "inusitado" de ainda existirem milhões de famílias sem acesso à luz elétrica em pleno século XXI, em comparação a profusão de cabos, fios, antenas e mídias avançadas nas regiões metropolitanas; seja pela reverberação provocada na cultura das tradições familiares e comunitárias; seja pela possibilidade aberta pelos meios de massa de estimular entre os habitantes um contato com um sistema mundo midiático (representações), existente além das cercanias do rural; seja pelas possibilidades de olhar para um estágio "primário" de presença e influência dos meios massivos ou para as possibilidades de futuro ingresso dos sujeitos nos meios online.

Neste texto, apresentamos o estudo de caso da comunidade rural Pau D’arco localizada no sertão do Estado do Piauí, que está inserida nos contextos pobres de um rural nordestino que teve em 2012 iniciada a instalação da eletricidade nas casas rurais por meio do "Programa Luz para Todos"3. A luz elétrica no espaço público, acompanhada da melhoria gradual da rede elétrica no privado das residências, sinaliza para a existência de uma nova experiência com as mídias eletrônicas na comunidade

\footnotetext{
3 O "Luz Para Todos" foi lançado em novembro de 2003 pelo Governo Federal, tendo como objetivo a inclusão elétrica das regiões mais remotas do interior brasileiro, tendo como foco os moradores da zona rural. De acordo com dados do Instituto Brasileiro de Geografia e Estatística (IBGE), até 2003, pelo menos 2 milhões de domicílios (80\% no meio rural) não tinham acesso a uma fonte de energia elétrica que fosse suficiente para o abastecimento básico de uma residência. Tendo essa como principal justificativa, o Governo tinha como meta instalar eletricidade para 10 milhões de brasileiros até o fim do ano de 2008, objetivo alcançado em meados de 2009. Até janeiro de 2013, o Luz para Todos chegou a 3,04 milhões de famílias, o que equivale a cerca de 14,83 milhões de pessoas residentes na área rural em todo o País, sendo que, desse percentual, 1,3 milhão de famílias atendidas ficam na região Nordeste, um total de 6,7 milhões de habitantes. No caso específico do estado do Piauí, o programa já atendeu a mais de 150 mil famílias, o que equivale a cerca de 700 mil pessoas.
} 
(antes da chegada da luz, o único meio de comunicação de massa na comunidade era o rádio de pilha), em especial a televisão. Observar realidades rurais como a de Pau D'arco seria perceber que vivemos em constante tensão entre o nosso tempo presente e também do que pode ser entendido como "realidades paralelas" as que estão nos grandes centros urbanos, principalmente ao que diz respeito a realidade comunicacional desses ambientes demonstradas por meio de uma reorganização social dos espaços de sociabilidades.

\section{Realidade comunicacional: a relação do indivíduo com os meios massivos}

Ao observarmos o evento da chegada da eletricidade em comunidades rurais estamos lidando com o "extra-midiático" citado por Braga (2011), uma vez que o acontecimento significa lançar um olhar sobre antigas tensões que envolvem as relações entre as tradições locais e a cultura de consumo dos conteúdos das mídias eletrônicas. Não olhamos para os aparatos midiáticos, nem para seus conteúdos e nem a cultura em si, mas para atravessamentos destes aspectos com uma realidade comunicacional (logo, socioculturais) que se modifica com a entrada das mídias: os possíveis reposicionamentos dos sujeitos entre si, as reorganizações cotidianas comunitárias e familiares, as novas circularidades de informações, bem como atualizações de sentido.

Esta articulação cultural dos sujeitos com um sistema mundo que chega pelos meios massivos (e, posteriormente, online) de modo mais intenso na contemporaneidade remete às discussões sobre as transformações no rural, à difusão entre culturas e às preocupações em torno de uma hibridação cultural entre o rural e o urbano. Já em 1956 o antropólogo Robert Redfield ${ }^{4}$, no clássico The primitive world and its transformations, analisou os acontecimentos que envolviam as transformações das populações chamadas "folk" (camponesas) e afirmou que o camponês surgiu junto com a cidade (aqui, no Brasil, a partir do início da urbanização e industrialização das

\footnotetext{
${ }^{4}$ Entre 1926 e 1930, o antropólogo norte-americano Robert Redfield viajou para o México para realizar pesquisas comparativas em quatro comunidades em diversas fases de confrontação com a sociedade moderna. Até 1950, Redfield se dedicou ao estudo sobre a vida dos camponeses nesse país. O livro "O mundo primitivo e suas transformações" marca a segunda fase do autor, que deixa os estudos folclóricos e camponeses para se dedicar a compreender as implicações da mudança cultural mais ampla, sintetizando os estudos antropológicos em um estudo his tórico da civilização.
} 
cidades e regiões pólo de desenvolvimento, na primeira metade do século passado), mas se caracterizou como um tipo humano entre o mundo "primitivo" e o "civilizado".

Podemos compreender mediante Redfield (1964) que, na época da formação das cidades, os rurais começaram a existir enquanto espaços de transformações "précivilizados" entre habitantes do "primitivo" e do mundo "civilizado".

Nossos historiadores das civilizações antigas, quando passam a descrever cidades tão antigas e altamente desenvolvidas quanto as do Egito ou da Mesopotâmia no terceiro milênio antes de Cristo, usam a palavra "camponês" para aqueles povos próximos cujos trabalhadores possibilitaram 0 aparecimento da cidade. A palavra indica um tipo humano. Ao invés de utilizá-la, como alguns o fizeram, para qualquer comunidade com produtores de pequena escala para o mercado, vamos reservá-la para um novo tipo. Foi preciso a cidade para que a palavra viesse a existir. Não havia camponeses antes das primeiras cidades. E os povos primitivos que sobrevivem e que não vivem em função da cidade, não são camponeses. Os índios Siriono não são camponeses; e nem os Navajo. É, porém, possível caracterizar positivamente os povos que o são. O camponês, como homem primitivo da tribo, é indígena. Ele vive onde sempre viveu e a cidade originou-se de um tipo de vida que também é seu, quanto aos costumes e crenças fundamentais (REDFIELD, 1964, p. 35).

Os espaços das cidades, portanto, colaboraram com a noção de espaço rural enquanto espaços "pré-civilizados" dos povos próximos da cidade, um "novo tipo" humano não-citadino. Os espaços rurais já nasceram enquanto uma cultura hibridizada e, ao longo das décadas, constituíram-se a partir da relação com os mundos urbanos que The serviram de referência (sedes municipais, pólos de desenvolvimento, capitais do Estado, etc), intensificando esta forma de vida hibrida que conserva traços das tradições tanto associadas ao tipo humano "primitivo" - ou comunitário, coletivo, local, próximo da natureza - quanto do tipo "civilizado" - individualizado, global, moderno. Ou seja, os espaços rurais, aos poucos, sofreram a experiência mais intensa da presença e influência dos espaços urbanos das cidades.

O evento da chegada da luz em uma comunidade rural significa um passo na direção deste "mundo civilizado" além das cercanias rurais. Em diversas microrregiões brasileiras, a eletrificação rural chegou com a urbanização, transformando regiões rurais em distritos com luzes nas ruas e nas casas, mas sem deixar os ares rurais. Tal evento que inicializou um processo de aproximação dos rurais das "civilizações" urbanas (assim como movimentos do tipo "volta à natureza" produziu comunidades alternativas 
mais inclinadas ao "primitivo") modifica traços comportamentais e simbólicos vinculados às atividades estritamente agrícolas e agropecuárias.

Contudo, vale salientar que a primeira fase da hibridação rural-urbano no início do século passado e a segunda marcada pela presença dos meios massivos na segunda metade do século $\mathrm{XX}$ se estabelece hoje, com a chegada da luz, de maneira diferente das décadas anteriores. Apesar da eletrificação rural no passado chegar acompanhada de mudanças tecnológicas (televisores coloridos, parabólicas, etc.), a população rural ainda estava se acostumando com a experiência da televisão, que ainda era vista como mais um móvel na sala de estar (LEAL, 1983). Atualmente os processos sociais nos espaços urbano-metropolitanos estão cada vez mais atravessados por processos de midiatização e o sistema mundo que chega pelas mídias intensifica os modos diferentes do jovem perceber a si e ao seu mundo rural. A juventude nos contextos rurais mais pobres de hoje, moradores dos lugares sem luz elétrica, frequentam os espaços das casas dos parentes e amigos nas cidades, da sede urbana do município, da escola do distrito, ou seja, lugares onde o sinal da internet seria um pouco melhor que no rural; onde os jovens já tiveram contato com as novas mídias nas salas de informática, ao manusear os aparelhos celulares dos amigos, etc.

\section{Informações dos meios massivos no mundo rural}

Mesmo nos contextos de eletrificação rural nas regiões mais pobres, as populações rurais diminuíram, mas não desapareceram. Os costumes se confundiram com traços culturais de "civilização" vistos a partir de um sistema mundo nas mídias. A hegemonia dos programas televisivos e do rádio; das figuras públicas e dos temas sociais mais inclinados ao não-rural (não estritamente vinculado ao agrícola e ao agropecuário) se estabelece (programas de auditório, telejornais populares, telenovelas com temáticas urbanas, programas esportivos). E olhando para os conteúdos rurais mais tradicionais na grade de programação dos meios massivos (programa Globo Rural, programas do canal Terra Viva, etc.) vemos ainda menos conteúdos voltados para o rural das familias da pequena agricultura familiar.

A presença física das mídias eletrônicas e as práticas de se comentar sobre seus conteúdos se integram à paisagem cotidiana da sociabilidade no rural, fazendo com que 


\section{míDiA

as pessoas se organizem tendo como referência os usos, as repercussões dos conteúdos e a programação das mídias. Para estas populações, a televisão e o rádio (como também a web) não estão na margem, mas no centro das comunicações já existentes, regulando socialmente as relações. Essas porções remanescentes do sistema mundo das mídias nos espaços rurais cotidianos conduzem os espaços rurais cada vez mais na direção de uma outra forma de vida hibridizada, mais distante da tradição rural.

O rádio e a televisão difundiram diversas informações e perspectivas de vida através de canções sertanejas (a moda caipira no Sudeste; o baião e o forró no Nordeste, etc), dos noticiários populares (em programas televisivos como "Brasil Urgente", "Cidade Alerta" e similares no rádio), programas de auditório (religiosos, da Inezita Barroso, do Rolando Boldrin, mas também outros como do "Ratinho", por exemplo), novelas (hoje mais da Record do que da Globo) e o futebol (nacional e internacional). Algumas informações encontravam resistências por parte da escola, da igreja e das associações - que posteriormente começaram a reposicionar seus discursos na medida da presença e influência dos conteúdos dos meios de massa.

Em transições complexas, podemos dizer que aspectos informacionais do mundo citadino circularam pela oralidade (contatos face a face, por telefone), pelas imagens (fotografias da cidade, por exemplo, enviadas por carta pelos migrantes), pela indumentária dos migrantes de retorno (SILVA, 2002). Depois trafegou pelo escriturístico entre os letrados (livros didáticos; cartas, jornais, revistas), mas teve intensa amplitude com os meios eletrônicos, o rádio e a televisão. A passagem da mediação do livro para a midiatização tecnológica foi bem dimensionada por José Luiz Braga (2007).

Assim a eletrificação rural se vincula a uma midiatização de base eletrônica no rural, que permitiu uma penetração tímida dos sinais de rádio, depois de televisão e agora da internet. Essa midiatização também só foi possível no rural com a melhoria da rede elétrica caseira e do acesso aos eletroeletrônicos (antenas de retransmissão, aparelhos eletrônicos). Desta forma, o massivo e o online ajudaram a diminuir o isolamento dos habitantes do rural, como também estimularam pensar o sistema mundo além das cercanias de modo diferente e menos dependente das instituições e tradições. 
Nesta história dos rurais brasileiros, a presença e influência das mídias eletrônicas merece um capítulo. Começa nos anos de 1980, com a proliferação das antenas parabólicas e, talvez mais a partir dos anos 2000, com as antenas dos canais por assinatura. As pessoas do rural passaram a ter acesso direto via satélite com os conteúdos midiáticos que narravam outros mundos ${ }^{5}$. Elas não estavam mais dependentes dos órgãos responsáveis pela manutenção das antenas que retransmitiam apenas os canais abertos tradicionais. O sinal de transmissão das empresas de comunicação parou de rebater nas grandes antenas situadas nos pontos mais altos da cidadezinha do interior, permitindo que um leque de programações televisivas entrasse direto nos lares rurais, dando autonomia ao sujeito no tocante ao acesso à informação. Foram os meios massivos de disseminação de informação que ampliaram aspectos do mundo urbano para o público rural, interferindo na mudança de alguns hábitos e costumes, afinando os sentidos e as experiências das pessoas com a cultura das grandes cidades.

Essa experiência pode ser visualizada principalmente entre os anos de 1920 a 1970 - período de desenvolvimento tecnológico e disseminação da cultura do cinema, do rádio e da televisão - quando prosperaram as discussões dos pesquisadores sociais em torno da problemática da interferência dos meios massivos nas culturas "menores", capazes de substituir e descaracterizar os costumes e valores dessas pequenas culturas. Até certo ponto, a preocupação seria pertinente, já que a relação das populações rurais com uma "cultura estrangeira" que chegava através dos meios eletrônicos de transmissão da informação significava também a acentuação da influência de uma "cultura dominante" sobre as "culturas subalternas".

\footnotetext{
${ }^{5}$ Muitos autores já afirmaram que as populações chamadas de periféricas passaram da pré-modernidade para a pós-modernidade sem o "estágio probatório" na modernidade, assim como os países ditos desenvolvidos. Não entendiam que as tais "populações periféricas" desenvolviam suas próprias formas de sociedade, tendo em vista suas diferentes realidades. Tais escolhas próprias estariam cada vez mais sofrendo a experiência da presença e da influência das mídias. "No caso do Brasil, chama a atenção a rapidez com que cresceu nas últimas décadas o acesso aos meios de comunicação, criando em todo o país um gigantesco público consumidor de bens simbólicos midiáticos. Segundo a Revista Mídia e Dados, em março de 1999 o número de aparelhos de televisão no Brasil era de 53 milhões e 573 mil, atingindo um total de 37 milhões de domicílios, em 4. 974 municípios, ou seja, 100\% do território nacional" (BRUCK, 2006, p.136).
} 


\title{
míDiA

Nos anos de 1960 alguns escritos acadêmicos das áreas de sociologia e antropologia se preocupavam com fatores culturais envolvidos entre processos de resistência às mudanças e de transformação nas localidades.

\begin{abstract}
Apenas recentemente vêm se acentuando nas povoações e no mundo rural, as transformações tendentes a provocar o abandono dos padrões tradicionais de vida. Desse modo, podemos observar aí, em estado quase puro, a persistência de elementos de estabilização do sistema social, contrários a qualquer forma de mudança na estrutura de relações sociais e econômicas, ao lado da penetração de outros que se lhe opõem e que forçam a incorporação de um novo estilo de vida (MOREIRA, 1963, p.30).
\end{abstract}

Moreira (1963) indagava sobre as representações, sentidos e ajustamentos se processando na transformação de uma cultura que "abandonava os padrões tradicionais de vida", consequência da tensão entre processos de resistência aos padrões estáveis do social e processos de mudança da estrutura das relações sociais que "forçam a incorporação de novo estilo de vida”. Já Milanesi (1972), em um dos primeiros estudos sobre comunicação social no Brasil, considerou como "violenta" a presença e influência da televisão em uma cidadezinha do interior paulista, pois "a programação organizada pela capital e para a capital, onde havia consumo mais amplo e desenvolvido, chegou ao interior com os mesmos esquemas" (MILANESI, 1972, p.214). O conflito de valores e significados se intensificou nos anos de 1970 com a multiplicação nos lares das pequenas cidades do interior e nos entornos rurais dos aparelhos de televisão:

\begin{abstract}
A introdução e a rápida disseminação desse novo elemento na coletividade [a sociedade de consumo via televisão] provocaram mudanças claramente perceptíveis, inclusive para aqueles que, dentro do processo, percebiam as alterações não apenas no meio, mas no próprio comportamento. Estas, vistas como normais dentro das transformações da sociedade, com resistência isolada e pouco significativa, foram aceitas. As alterações observadas situaram-se ao nível dos costumes, entendidos aqui como padrões de comportamento que o meio sancionou; ao nível das atitudes, caracterizadas como tendência para determinada postura em relação ao meio. Novas atitudes e costumes puderam ser identificados, pois se manifestavam externamente. Se as pessoas deixavam de fazer visitas ou se o conteúdo das conversas restringia-se aos programas televisados, isso poderia ser notado e era. Já os novos valores, compreendidos como opinião e atitude em relação a objetos, posturas, regras, técnicas, pouco foram observados, ainda que mantivessem estreita ligação com atitudes e costumes (MILANESI, 1972, p. 14).
\end{abstract}

Milanesi (1972) explicou que a televisão na cidadezinha do interior não deveria ser encarada apenas como passatempo. Nas entrevistas do pesquisador, as pessoas 
reagiam com espanto e indignação à hipótese de a televisão deixar de existir na vida deles, pois "o telespectador reage como se estivesse sendo logrado, perdendo os seus direitos. Por isso, a perda definitiva da televisão pode ser vista como uma catástrofe" (MILANESI, 1972, p. 212). Mais do que divertimento inócuo, a televisão teria uma "força didática", segundo o autor, capaz de proporcionar retenção das informações de maneira mais completa que o ensino sistemático das escolas públicas, já que o meio audiovisual atuava de maneira demorada entre as pessoas:

Tudo que se refira à programação da TV é do conhecimento geral. Inclusive, as pessoas que ainda não compraram o seu aparelho receptor dão respostas às perguntas sobre horário dos programas, nome dos apresentadores, artistas de novelas e outras. Já as questões relativas ao aprendido nas escolas criam embaraços (MILANESI, 1972, p. 212).

Podemos dizer também que, tanto na cidadezinha quanto no seu entorno rural desta época, os meios massivos se tornaram aliados em um processo irreversível de transformação da cultura dos sujeitos habitantes dessas localidades $^{6}$. A televisão nos anos de 1970, por exemplo, funcionou como um mecanismo de educação informal, pois onde não havia escola rural tinha um aparelho de tevê ${ }^{7}$ - diferente da função que a televisão possui hoje. No entanto, igualmente a televisão aproximava culturas, o que se configurou, de um lado, uma preocupação para os pesquisadores e, do outro, uma necessidade às populações dessas regiões: toda a informação que vinha de fora passou a ser encarada como conhecimento; assistir à televisão se tornou um direito à informação e ao lazer. Por isso, na visão de mundo das populações do interior, a relação com os sentidos impressos nos conteúdos dos meios massivos era vista como normal e bemvinda para o progresso sociocultural da região.

\footnotetext{
${ }^{6}$ Entre os meios eletrônicos de transmissão de informações, a televisão sempre se destacou como o meio preferencial nos contextos de vida popular. Para os lares rurais, o meio televisão, aos poucos, abriu os sentidos dos sujeitos para o mundo estrangeiro, o outro estranho na tela que entra nos lares das famílias, propondo outros hábitos, diferentes falas, costumes e sentidos. Esta relação mediada pela experiência com o outro na televisão se tornou es sencial à vida das pessoas nas cidadezinhas do interior - como observou Milanesi (1972) - pois a informação sobre o mundo além das cercanias do distrito e seu entorno rural se transformou em um item de primeira necessidade, um direito conquistado. Lá na distante década de 1960, a população da cidadezinha do interior paulista e de seu entorno rural já dava valor a tal experiência (MILANESI, 1972).

${ }^{7}$ Alguns programas na tevê aberta eram considerados educativos, como o Vila Sésamo (TV Globo), por exemplo. Havia um quadro no programa que dizia: "Esse programa é patrocinado pela letra A" e os apresentadores seguiam dando exemplos de palavras com a letra A.
} 
No decorrer da experiência das pessoas com as mídias de massa se mostrou um processo próprio de racionalização das informações por parte dos indivíduos, tanto das informações escritas e orais que circulavam pela região quanto das mediadas pelas tecnologias. Aos poucos, as pessoas entrelaçavam alguns elementos de certos conteúdos das mídias com essa lógica própria de racionalização de informações ${ }^{8}$, produzindo uma leitura social da mídia que se emaranhava com a vida. Em alguns casos, podia até mobilizar inclusive alterações nas leis, contestações das normas e dos valores instituídos na comunidade local.

Os habitantes no rural, portanto, sempre se mostraram ativos no processo de relação com os meios eletrônicos de transmissão de informação, preservando seus costumes, mas se adaptando às mudanças ou necessitando se apoiar em suas experiências de vida para entender o mundo além do rural via mídia, sem que esse movimento tenha sido identificado como "substituição" ou "descaracterização" dos padrões de comportamento. A televisão como "janela para o mundo" permitiu às populações rurais experimentarem o pensar sobre o outro que se via nos meios massivos, partilhando sentidos e informações e tornando os meios indispensáveis à experiência de vida.

Falamos de textos históricos (MOREIRA, 1963; MILANESI, 1972) preocupados na época com a intensificação da relação da sociedade moderna com as comunidades tradicionais, ainda mais tendo em vista a indústria cultural. A cultura e a vida familiar se tornaram objeto de estudo de várias pesquisas que vieram em seguida, preocupadas com a penetração dessa "indústria do espírito" e com a "colonização da alma" na esfera privada doméstica, um modelo que recortava do real alguns pedaços das culturas para fabricá-las industrialmente e vendê-las comercialmente (LEAL FILHO, 1988). Como dissemos, esses foram textos marcados por sua época.

\section{Estudo de caso: comunidade rural de Pau D’Arco do Piaú.}

\footnotetext{
${ }^{8}$ José de Souza Martins (2012), nas entrelinhas, explicou que o habitante do rural tem uma lógic a própria, diferente dos habitantes das cidades, bem ali quando ele fala que utilizou a concepção sociológica de "situação de classe social" para "indicar coincidências e diferenças entre operários e camponeses" (p. 58) e, a partir de então, desenvolve tais diferenciações ao longo de 57 páginas do livro A sociedade vista do abismo.
} 


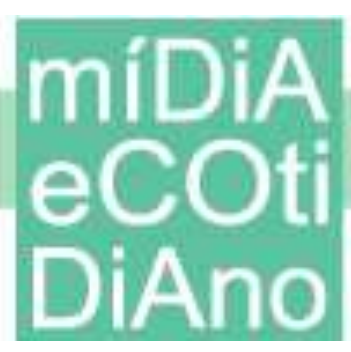

Quando se fala em comunidades rurais brasileiras, é importante ressaltar a significativa diferença socioeconômica entre o Norte-Nordeste e as demais regiões do país, bem como as diferentes populações do próprio Nordeste brasileiro (pescadores no litoral, sertanejos da caatinga, pessoas que moram em regiões mais desenvolvidas do agreste, indígenas, habitantes de minúsculos distritos, de assentamentos rurais, etc.).

Em geral, os jovens nestes contextos mais pobres do rural nordestino estariam mais próximos daquilo já dito por Silva (2002) sobre os jovens do sertão pernambucano, acostumados às migrações para São Paulo após os 18 anos, em busca de continuar os estudos e "melhorar de vida" no centro urbano.

A comunidade de Pau D'arco, nosso objeto de pesquisa, faz parte da zona rural do município piauiense de Wall Ferraz, a uma distância de $329 \mathrm{~km}$ da capital Teresina. A cidade fica localizada na região do sertão do Estado, sua população é de 4.280 habitantes, sendo que 3.114 (73\%) moram na área rural do município, de acordo com dados do último censo do IBGE $^{9}$ (Instituto Brasileiro de Geografia e Estatística) realizado no ano de 2010.

Pau D'arco está localizada a $13 \mathrm{~km}$ de distância da sede urbana do município, à qual se liga por meio de uma estrada de terra. A comunidade foi fundada em meados dos anos de 1940 por famílias tradicionais da região. Conta, atualmente, com 73 habitantes, em sua grande maioria ligada por laço de parentesco.

A estrutura espacial da comunidade é constituída por casas de tijolos e telhas de barro, com aspecto simples e humilde. A grande maioria das residências tem quintais e currais feitos de madeira e um grande terreiro limpo na frente com árvores (pau d'arcos ${ }^{10}$, umbuzeiros, tamarindos e outros) para fazer sombra e servir de espaço de socialização entre família e vizinhos.

A comunidade tem como principal fonte econômica o plantio e cultivo de mandioca para a produção de farinha e tapioca, que são comercializadas nas cidades vizinhas. Além da mandioca, também se cultiva feijão, arroz e milho para o consumo da família e dos animais, sendo assim uma agricultura de subsistência. Outra atividade

\footnotetext{
${ }^{9}$ C.f.: www.ibge.gov.br/home/estatistica/populacao/censo2010/tabelas_pdf/total_populacao_piaui.pdf. Acessado em 25 de junho de 2015.

10 Árvore que também é conhecida como Ipê. A comunidade estudada recebeu este nome por ser uma região que tem a árvore em abundância.
} 


\section{míDiA \\ 政 \\ DiAno}

praticada em Pau D’arco é a criação de gado (bovinos, caprinos, ovinos, súnos e de aves), criações pequenas para o consumo da familia e a venda de um ou dois animais para fazer renda extra.

Atualmente, a comunidade não tem escolas e nem posto de saúde. Quem estuda se desloca diariamente para a sede do município em ônibus escolar da prefeitura. Outros serviços públicos estão em Wall Ferraz, em municípios maiores e alguns deles na capital Teresina. Tanto Pau D'arco quanto Wall Ferraz não têm emissoras de rádio ou televisão, nem jornais e portais de internet. O conteúdo informativo acessado pela população vem de veículos de comunicação local de outros municípios, como Oeiras, Picos e Teresina, além das redes de comunicação nacionais. Tais características de Pau D'arco seriam muito comuns em milhares de outras comunidades rurais mais afastadas dos grandes centros do nordeste brasileiro. As pessoas que residem nesses espaços têm o rádio de pilha muitas vezes como o principal e único veículo.

Desde os anos de 1990 observamos em várias visitas à comunidade que o cenário rural não teve grandes alterações, exceto as migrações de uns e outros para as cidades vizinhas que quando podem retornam para a comunidade para visitar os parentes.

As mudanças de cunho temporal e migratório contrastam com a inércia da paisagem do lugar: as mesmas casas simples com calçadas largas, o campinho de futebol, a capela para as reuniões e novenas de domingo, o prédio antigo do "grupo" escolar, as roças em frente às casas com os animais de carga sempre a postos para o transporte de água ${ }^{11} \mathrm{e}$, às vezes, vaqueiros e suas boiadas. Cotidiano comum de cadeiras nas calçadas, da sela pendurada na parede, da banca de potes ${ }^{12}$ e do antigo rádio de pilhas para distrair com músicas e informar dos acontecimentos.

Contudo, em Pau D’Arco, este contexto vem mudando desde a chegada da energia elétrica na comunidade em 2012, que permitiu a instalação de aparelhos de televisão. De fato, hoje, na comunidade, podemos observar, em pleno século XXI, algo característico dos anos de 1980 quando a eletrificação rural foi mais intensa no país: o abandono de alguns costumes cotidianos e a ausência das pessoas nas ruas e calçadas. $\mathrm{O}$ rádio, antes a pilha, cedeu espaço ao rádio ligado à eletricidade (que aos poucos perderá

\footnotetext{
${ }^{11}$ Nascente de água que brota do solo.

${ }^{12}$ Móvel de madeira para colocar os potes de barro para reservar a água.
} 
espaço para o rádio no celular). Todavia, mesmo com traços próximos aos que aconteceram nas comunidades rurais em que a eletricidade chegou em meados da década de 80 do século XX, as modificações que estão ocorrendo em lugares como Pau D’arco são próprias de uma época marcada por processos de massificação e também, em menor proporção, de "midiatização" dos meios online, o que traz novas experiências a serem observadas.

\section{A tática do download}

Sem sinal de internet e, consequentemente, sem computadores conectados em suas casas, o contato dos jovens de Pau D'arco com o conteúdo midiático vem de forma diferente do usual. Este contato está presente principalmente quando os jovens estão na sede do município e acessam suas redes sociais, trazendo para os demais moradores o download de notícias, fotos, áudios e vídeos dos parentes que vivem em outros municípios e estados. Sendo assim, as informações que antes só vinham por meio de cartas (textos e fotografias) que eram lidas pelos letrados da comunidade (grande parte dos mais velhos da comunidade não possuem letramento), hoje chega via downloads pelos celulares (não só texto e imagem, mas audiovisuais) de modo mais rápido, esteticamente modificada e diferenciada.

Já com a televisão os moradores estão tendo que se adaptar ao sinal digital do aparelho, uma vez que, com a transição do analógico para o digital, os televisores de tubo que estão presente em 20 das 22 casas da comunidade estão sendo substituídos ou ligados em aparelhos conversores. Ou seja, em cinco anos Pau D'arco se transformou em termos dos processos de massificação e midiatização, iniciado com a chegada da eletricidade, que passa atualmente pelas adaptações tecnológicas e pela convivência com os aparelhos digitais.

\section{Televisão em Pau D’arco}

Até 2012 a iluminação em Pau D'arco era por meio de lamparinas movidas a querosene. A água para o consumo diário era carregada no lombo de animais ou em latas pelos próprios moradores. E a comunicação se limitava a face a face ou por meio de avisos e recados via rádio. Para informar algo para a comunidade, era preciso se 


\section{míDiA \\ ecc

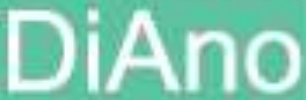

deslocar até Pau D’arco, mandar via mensageiros ou deixar recado no rádio, pagando pela locução de avisos.

Hoje com a chegada da luz, além da tática do download, (recebimento de notícias dos parentes que vivem distante por meio de mensagens baixadas via redes sociais) realizada pelos mensageiros, também tem o aparelho telefônico em cada residência da comunidade ligado pela antena de telefonia rural, o que permite recados diários. Além disto, a eletricidade permitiu a instalação de um poço artesiano, da encanação de água nas casas dos moradores e de uma bomba elétrica para cada morador, que aposentou os animais e as ânforas que auxiliavam no transporte da água. Além da água encanada e da televisão, agora também há itens de primeira necessidade (geladeira e ventilador).

Assim como descreveu Leal (1983), conseguimos observar mais de 30 anos depois, com a chegada da luz elétrica na comunidade rural, o lugar de importância da televisão na sala de estar, em um móvel alto de destaque e normalmente rodeada por porta-retratos, a bíblia, imagens de santos e sempre coberta (quando não está ligada) com um pano bem decorado para evitar que seja atingida pela poeira.

Além do destaque do aparelho no ambiente da casa, o mais notável seriam as mudanças de comportamento. Rituais de sociabilidade antes praticados cotidianamente pelos moradores, hoje já não são tão visíveis. Antes era comum ver as crianças de Pau D'arco brincando ao ar livre, jogando futebol no campinho, fazendo casinhas de bonecas debaixo das árvores. Com a televisão vê-se poucas crianças correndo pelos terreiros e arredores das casas, estando elas em sua maioria (depois da escola) em frente ao aparelho de tevê vendo sobretudo a programação infantil do canal SBT ${ }^{13}$. O horário das conversas nas calçadas das casas - lugar para reunir a família e os vizinhos para longas conversas que iam até tarde da noite - se modificou para depois do Jornal Nacional da Rede Globo, geralmente com uma pauta de conversas condicionada por aquilo visto no noticiário noturno. Se houve mudança no horário da conversa, também mudou o horário de dormir: anteriormente os moradores iam "dormir junto com as galinhas" (dormir cedo, por volta das 19 horas) agora só vão dormir depois das 22

\footnotetext{
13 Informação adquirida em visitas prévias anotadas em diário de campo sobre o consumo de mídia realizada na comunidade Pau D'arco em janeiro de 2017.
} 


\title{
ecot DiAno
}

horas. Tal horário também se modifica conforme a programação das novelas e do jogo de futebol.

Silva (2014) estudou diferentes figuras midiáticas admiradas pelos jovens no rural mineiro. Com base no autor, observamos em entrevistas realizadas com todos os habitantes de Pau D'arco também o surgimento desses novos ídolos. Antes os locutores do rádio eram os mais admirados pela população, nunca associados à imagem física beleza, estilo, jeito de ser, indumentária. Era o talento do cantar ou do domínio com as palavras que contava.

\begin{abstract}
Antes da televisão, quem a gente admirava aqui era o padre Marcelo Rossi porque além de cantar bem, também rezava uma missa muito bonita...falava bonito. Eu também gosto do Roberto Carlos. Mas, a meninada mais nova de hoje, gosta mais do povo que vê na tevê, e vestem igual a eles, cortam o cabelo tipo o do Neymar [...] ${ }^{14}$ (ALAÍDE RIBEIRO, 2017).
\end{abstract}

Neste ponto, observamos com mais intensidade a presença e influência dos conteúdos midiáticos: a passagem da oralidade e do escriturístico para o massivo e midiático e suas interferências na realidade vivida pelos moradores de Pau D'arco. E a fase do encantamento com o contato com um sistema mundo midiático além das cercanias rurais.

\section{Considerações finais}

O aspecto do encantamento pela televisão da fase inicial e suas mudanças de comportamento já observadas por outros pesquisadores do campo da Comunicação, mas igualmente pelas táticas de download dos jovens que se deslocam entre o rural e o urbano trazendo mensagens audiovisuais e de texto para os familiares; as rodas de conversas nas calçadas com temáticas condicionadas pelos noticiários televisivos; o contato estético com um sistema mundo além do rural e o estímulo das narrativas nãorurais no próprio jeito de ser e de se perceber no rural; as possibilidades do crescimento do online em Pau D’Arco. Todos esses aspectos socioculturais e simbólicos se multiplicam na comunidade rural nordestina e configura o evento da chegada da luz em Pau D’Arco como diferente de outros tempos, de outros contextos. Ainda restam muitas

\footnotetext{
${ }^{14}$ Entrevista gravada, concedida em 17 de janeiro de 2017 na comunidade Pau D’arco do Piauí.
} 


\section{ecot \\ DiAno}

perguntas nesta pesquisa ainda em andamento: observar a circularidade discursiva dos moradores de Pau D’Arco nas redes sociais (a partir das táticas de download), os temas sociais mais comuns, as figuras das mídias que mais se destacam, os programas mais assistidos, etc. Pau D’Arco, portanto, configura-se como um estudo de caso interessante para observações sobre as marcas da passagem da oralidade para a massificação e posteriormente a midiatização; sobre modos de se circular informação: das mensagens baixadas pelas redes sociais para as rodas de conversas nas calçadas; dos meios massivos para os espaços de sociabilidade.

\section{Referências Bibliográficas}

BRAGA, J.L. Midiatização como processo interacional de referência. In: MÉDOLA, A.S.; ARAÚJO, D.C.; BRUNO, F. (Orgs.). Imagem, visibilidade e cultura midiática. Porto Alegre: Sulina, 2007. Constituição do campo da comunicação. Verso e Reverso, n.25, 2011, p.62-

77.

BRUCK, M.S. Rádio e Televisão: mídia eletrônica e cultura no Brasil. In: PINTO, J.; SERELLE, M. (Orgs.). Interações Midiáticas. Belo Horizonte: Autêntica, 2006, p.135151.

LEAL, O.M.F. Leitura Social da Novela das Oito. Dissertação (Mestrado em Antropologia, Política e Sociologia do Instituto de Filosofia e Ciências Humanas). Universidade Federal do Rio Grande do Sul, 1983.

LEAL FILHO, L.L. Atrás das Câmeras: Relações entre Cultura, Estado e Televisão. $2^{\mathrm{a}}$ ed. São Paulo: Summus, 1988.

MARCONI, M. de A.; PRESOTTO, Z. M. N. Antropologia: uma Introdução. São Paulo: Atlas, 1992.

MELlO, L.G. de. Antropologia Cultural. Iniciação, Teoria e Temas. $2^{\mathrm{a}}$ ed. Petrópolis/RJ: Vozes, 1983.

MILANESI, L.A. O paraíso via embratel: o processo de integração de uma cidade do interior paulista na sociedade de consumo. Rio de Janeiro: Paz e Terra, 1978.

MOREIRA, M. S. F. O estudo sociológico de comunidades. Revista de Antropologia. São Paulo, n.11 (1-2), jun-dez, 1963. 
REGUILLO-CRUZ, R. Ciudad y Comunicación: densidades, ejes y niveles. Diálogos de la Comunicación (Felafacs), v.1, n. 75, 2007.

REDFIELD, R. O mundo primitivo e suas transformações. Rio de Janeiro/Usaid: Centro de Publicações Técnicas da Aliança/Editora da Fundação de Sociologia e Política de São Paulo, 1964.

SIQUEIRA, D.; OSÓRIO, R. O conceito de Rural. In: GIARRACA, N. (Org.). Una nueva ruralidad en América Latina? Ciudad Autónoma de Buenos Aires/Argentina, 2001, p.67-79.

SILVA, R. D. G. Juventude em trânsito: atravessamento de sentidos e narrativas televisivas no meio rural. Tese (Doutorado em Comunicação e Sociabilidade). Universidade Federal de Minas Gerais, 2014.

Uma tradução simbólica da metrópole: imaginário de jovens rurais sobre São Paulo e suas relações comunicativas com jovens paulistas. Dissertação (Mestrado em Comunicação Rural). Universidade Federal Rural de Pernambuco, 2002.

SILVA, R. D. G.; SOARES, J.B. Consumo de mídias, interações e valores entre jovens rurais mineiros. XXI Encontro Anual da Associação dos Programas de PósGraduação em Comunicação (Compós), Universidade Federal de Juiz de Fora, Juiz de Fora, jun. de 2012. 